Check for updates

Cite this: RSC Adv., 2017, 7, 51021

Received 25th August 2017

Accepted 24th October 2017

DOI: 10.1039/c7ra09429a

rsc.li/rsc-advances

\title{
A microporous cationic metal-organic framework for the efficient removal of dichromate and the selective adsorption of dyes from water $\uparrow$
}

\author{
Mingming Guo, Huadong Guo, (DD* Siyu Liu, Yingying Sun and Xianmin Guo* \\ A unique microporous cationic metal-organic framework, namely $\left[\mathrm{Cd}(\mathrm{tipo})(\mathrm{HCOO})\left(\mathrm{H}_{2} \mathrm{O}\right)\right] \cdot \mathrm{NO}_{3} \cdot \mathrm{DMF}(1)$, \\ has been synthesized and structurally characterized [tipo $=\operatorname{tris}(4-(1 \mathrm{H}$-imidazol-1-yl)phosphine oxide)]. \\ This compound exhibits rapid and selective separation of methyl orange. Meanwhile, it has also been \\ developed as a potential adsorbent material for the efficient removal of $\mathrm{Cr}_{2} \mathrm{O}_{7}{ }^{2-}$ from aqueous solutions \\ with a high uptake of up to $228 \mathrm{mg} \mathrm{g}^{-1}$.
}

\section{Introduction}

Nowadays, with the growth in population and the development of the manufacturing industry, water pollution has become one of the most serious global environmental issues. Organic dyes and metal ions are the major pollutants in water, which not only contaminate aquatic and soil ecosystems, but also harm human health because of their toxicity and carcinogenicity. ${ }^{1}$ Among various techniques for the removal of water pollutants, adsorption is the most attractive method owing to its simplicity and efficiency. ${ }^{2}$ Consequently, numerous adsorption materials have been extensively investigated, including carbon nanotubes, ${ }^{3}$ clay, ${ }^{4}$ zeolites, ${ }^{5}$ sol-gel adsorbents ${ }^{6}$ and polymer resins. ${ }^{7}$ However, these adsorbents often face some problems like low adsorption capacities, slow adsorption kinetics, complex preparation processes, and chemical or thermal instabilities. The

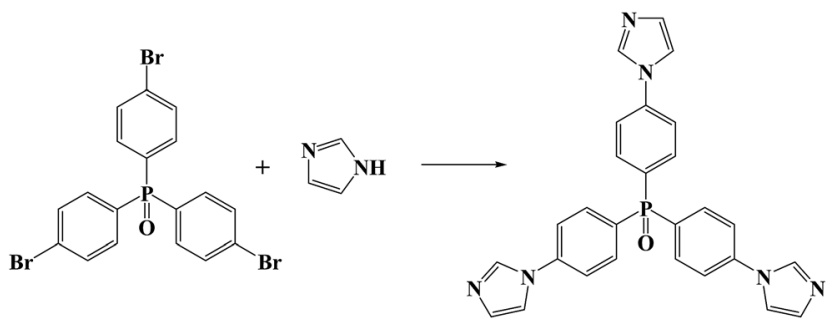

Scheme 1 The synthesis of tris(4-(1H-imidazol-1-yl)phosphine oxide). development of high-performance adsorbents for water pollutants is still a challenge (Scheme 1).

As a new class of porous solid material, metal-organic frameworks (MOFs) have attracted considerable research attention. ${ }^{8}$ Compared to existing inorganic/organic microporous materials, the pore size and surface areas of MOFs can be finely tuned through the rational selection of metal ions and the design of organic ligands, which can effectively enrich guest species. ${ }^{9}$ Recently, progressive efforts have been dedicated to the construction of microporous MOFs with ionic frameworks. By counter-ion exchange, the suitably charged guest motifs, including ions, organic dyes or small coordinative molecules, can not only be encapsulated into the pores of the nets, but also interact with the charged frameworks through electrostatic forces. ${ }^{10}$ Thus, the adsorption affinity between the guest motifs and the host frameworks definitely improves, which is crucial for the kinetics of adsorption-desorption. Such MOF materials are expected to be reasonable candidates to eliminate chargeable dyes and metal pollutants from wastewater.

In this work, we synthesized a tripodal neutral ligand, tris(4(1H-imidazol-1-yl)phosphine oxide) (tipo) as the building unit, in view of its long size and rigid conformation that facilitates control in the design and assembly of metal-containing aggregates with open frameworks. The resulting microporous cationic MOF $\left[\mathrm{Cd}(\right.$ tipo $\left.)(\mathrm{HCOO})\left(\mathrm{H}_{2} \mathrm{O}\right)\right] \cdot \mathrm{NO}_{3} \cdot \mathrm{DMF}(\mathbf{1})$ shows efficient removal of dichromate and selective adsorption of methyl orange from water.

\section{Experimental section}

\section{Materials and instrumentation}

The ligand tipo was synthesized according to the literature method. ${ }^{11}$ All other starting materials were of analytical grade and used as received without further purification. Elemental analyses (C, H, N) were performed with a Perkin-Elmer 240C

elemental analyzer. TGA was performed on a Perkin-Elmer TG-7

\footnotetext{
Department of Chemistry, Changchun Normal University, Changchun, 130032, $P . R$ China. E-mail: hdxmguo@163.com; xian_min@hotmail.com; Fax: +86-431 86168210; Tel: +86-431-86168210

$\dagger$ Electronic supplementary information (ESI) available: XRD and TGA. CCDC 1568832. For ESI and crystallographic data in CIF or other electronic format see DOI: $10.1039 / \mathrm{c} 7 \mathrm{ra09429a}$
} 
analyzer heated from 30 to $1000{ }^{\circ} \mathrm{C}$ under nitrogen (Fig. S1 in ESI $\dagger$ ). Powder X-ray diffraction (PXRD) data were recorded on a Bruker D2 Phaser (Fig. S2 in ESI $\dagger$ ). UV-vis adsorption spectra were collected on a Shimadzu UV-3101PC spectrophotometer to monitor the exchange progress.

\section{Synthetic procedures}

Synthesis of tris(4-(1H-imidazol-1-yl)phosphine oxide) (tipo). A mixture of $\mathrm{Cu}_{2} \mathrm{O}(0.07 \mathrm{~g}, 0.5 \mathrm{mmol})$, tris(4-bromo)phosphine oxide $(5.14 \mathrm{~g}, 10 \mathrm{mmol})$, imidazole $(4.08 \mathrm{~g}, 60 \mathrm{mmol})$ and $\mathrm{K}_{2} \mathrm{CO}_{3}(8.29 \mathrm{~g}, 60 \mathrm{mmol})$ in anhydrous DMF $(30 \mathrm{~mL})$ was stirred at $150{ }^{\circ} \mathrm{C}$ for $48 \mathrm{~h}$ in a $100 \mathrm{~mL}$ two-necked round-bottom flask under $\mathrm{N}_{2}$. The reaction mixture was filtered, and then the filtrate was added to $300 \mathrm{~mL}$ of $\mathrm{H}_{2} \mathrm{O}$. The deposit was filtered and washed with water and dried in a vacuum to afford the product in 54\% yield. Anal. calcd. for $\mathrm{C}_{27} \mathrm{H}_{21} \mathrm{~N}_{6} \mathrm{OP}$ (\%): C, 68.06; H, 4.44; N, 17.64. Found: C, 67.94; H, 4.34; N, 17.54.
Synthesis of $\left[\mathrm{Cd}(\mathrm{tipo})(\mathrm{HCOO})\left(\mathrm{H}_{2} \mathrm{O}\right)\right] \cdot \mathrm{NO}_{3} \cdot \mathrm{DMF}$ (1). A mixture of $\mathrm{Cd}\left(\mathrm{NO}_{3}\right)_{2} \cdot 4 \mathrm{H}_{2} \mathrm{O}(0.308 \mathrm{~g}, 0.1 \mathrm{mmol})$, tipo $(0.0476 \mathrm{~g}$, $0.1 \mathrm{mmol}), \mathrm{DMF}(8 \mathrm{~mL})$ and $\mathrm{HNO}_{3}(1 \mathrm{~mL}, 0.2 \mathrm{M})$ was placed in a Teflon reactor $(20 \mathrm{~mL})$ and heated at $80{ }^{\circ} \mathrm{C}$ for 2 days and then allowed to cool to room temperature. The colorless crystals were washed with ethanol and air-dried. Yields: $62 \%$ (based on tipo). Anal. Calcd for $\mathrm{C}_{31} \mathrm{H}_{31} \mathrm{~N}_{8} \mathrm{O}_{8} \mathrm{PCd}$ : C, 47.31; H, 3.97; N, 14.24. Found: C, 47.22; H, 3.82; N, 14.35 .

$\mathrm{X}$-ray crystallography. Single-crystal XRD data for compound 1 were recorded on a Bruker Smart Apex II diffractometer with graphite monochromatized Mo K $\alpha$ radiation $(\lambda=0.71073 \AA)$ at 120(2) K. Absorption corrections were applied using the multiscan technique. All structures were solved by direct methods using SHELXS-97 (ref. 12) and refined with full-matrix leastsquares techniques using the SHELXL-97 (ref. 13) program within WINGX. Non-hydrogen atoms were refined with anisotropic temperature parameters. The hydrogen atoms of the
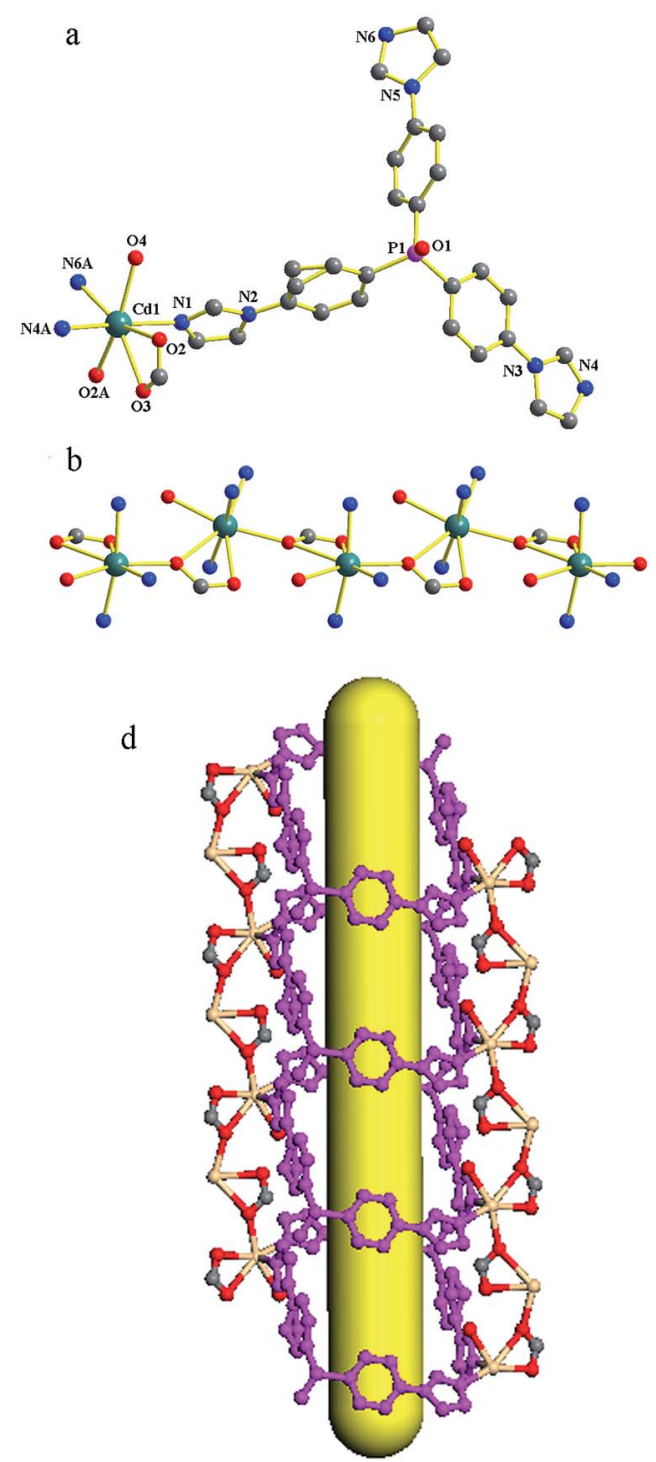
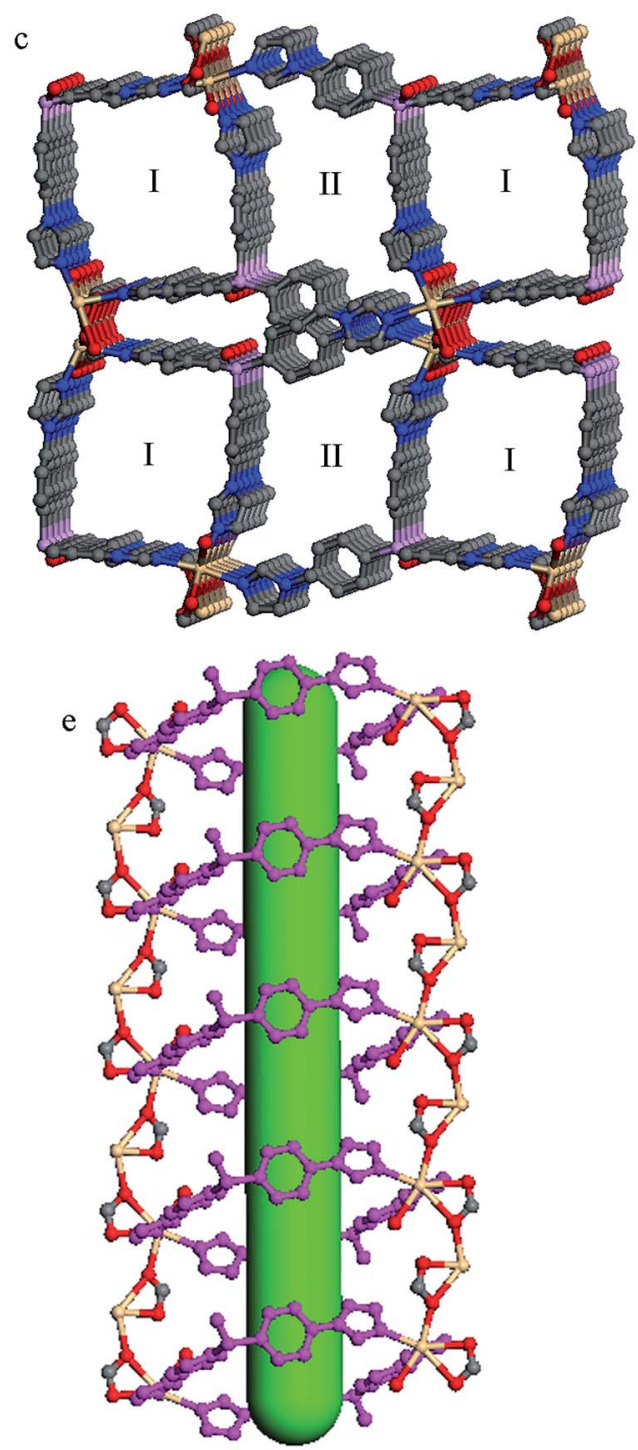

Fig. 1 (a) The coordination environment of $\mathrm{Cd}(\mathrm{II})$ atoms in 1 . Hydrogen atoms and $\mathrm{NO}_{3}{ }^{-}$are omitted for clarity. (b) The 1D chain constructed by $\mathrm{Cd}($ II) atoms and formates. (c) The 3D framework presented 1D channels (marked as I and II). (d) and (e) The perspective views of the 1D channels with different dimensions. 
organic ligands were refined as rigid groups. For the high vibration, the disordered $\mathrm{C} 5$ was refined using $\mathrm{C}$ atoms split over two sites with a total occupancy of 1 and handled by isotropic refinement. The SQUEEZE option of PLATON ${ }^{\mathbf{1 4}}$ was used to eliminate the contribution of disordered guest molecules to the reflection intensities. The formulas of 1 were calculated by considering the thermogravimetric analysis, elemental analysis and single-crystal structures results, respectively. The detailed crystallographic data and structure refinement parameters for $\mathbf{1}$ are summarized in Table S1 in the ESI. $\dagger$

\section{Results and Discussion}

\section{Structural characterization of 1}

Compound 1 crystallizes in a monoclinic space group $P 2_{1} / c$. In the asymmetric unit, one crystallographically unique $\mathrm{Cd}(\mathrm{II})$ atom, one tipo ligand, one formate ion, one coordinated water molecule and one $\mathrm{NO}_{3}{ }^{-}$anion exist. The anionic formate ion is generated through the hydrolysis of DMF molecules under solvothermal conditions. As shown in Fig. 1a, the Cd(II) atom is coordinated by three $\mathrm{N}$ atoms from three tipo ligands (Cd-N 2.2901(17)-2.3474(17) $\AA$ ), and four O atoms from two formate ions and one water molecule (Cd-O 2.3560(14)-2.6248(14) A). The Cd(II) to $\mathrm{O} / \mathrm{N}$ distances and the bond angles are within the normal range (Table $\mathrm{S} 2$ in the ESI $\dagger$ ). The formate ion adopts a syn,syn,anti-bidentate coordination mode and connects Cd(II) atoms into a 1D infinite linear chain (Fig. 1b). These chains are combined by tipo ligands into a 3D framework. As shown in Fig. 1c, along the $c$ axis, the framework presents two kinds of 1D rectangular channel for the packing of tripodal tipo ligands. The window sizes of the channels are about $8.7 \times 10.0 \AA^{2}$ (marked as I) and $8.2 \times 8.7 \AA^{2}$ (marked as II), respectively. The void space accounts for approximately $40.8 \%$ of the whole crystal volume as obtained by PLATON analysis, which is occupied by the disordered DMF molecules and $\mathrm{NO}_{3}{ }^{-}$ions.

\section{Adsorption capability of 1 towards organic dyes}

Organic dyes have been widely used in the textiles, paper, medicine and printing industries, and water polluted by dyes poses a significant threat to the environment and to human health. ${ }^{15}$ In view of the highly charged porous structures, the dye-capture ability of $\mathbf{1}$ was evaluated using three selected dyes (i.e., methylene blue (MB), methyl orange (MO) and rhodamine $\mathrm{B}(\mathrm{RhB})$ ) as typical pollutant models. The adsorption experiments were run as follows: $5 \mathrm{mg}$ of 1 was immersed into $10 \mathrm{~mL}$ of the aqueous dye solution $\left(5.0 \times 10^{-5} \mathrm{M}\right)$. The clear solution was measured by UV/vis spectroscopy after centrifuging to monitor the organic dye concentration at different time intervals. As shown in Fig. 2a, the yellow solution of MO immediately faded to colorless within 20 minutes. Such a significant decrease in color intensity was consistent with the UV/vis spectroscopic results. However, for $\mathrm{MB}$ and $\mathrm{RhB}$, no obvious solution color or absorbance intensity change was observed even after 1 hour (Fig. $2 \mathrm{~b}$ and c). The results above show the potential selective separation ability of $\mathbf{1}$ towards MO, which were also confirmed by the competitive adsorption experiments of MO in the presence of other dyes. $5 \mathrm{mg}$ of 1 was immersed in $10 \mathrm{~mL}$ of the aqueous dye solutions of $\mathrm{MO} / \mathrm{MB}$ and $\mathrm{MO} / \mathrm{RhB}$, which were prepared by mixing the two dyes in equal volumes, with a concentration of $5.0 \times 10^{-5} \mathrm{M}$ for each dye. As shown in Fig. 3, the colors rapidly changed from green for $\mathrm{MO} /$ $\mathrm{MB}$ to blue for $\mathrm{MB}$ and from orange for $\mathrm{MO} / \mathrm{RhB}$ to pink for $\mathrm{RhB}$, respectively. Both UV/vis spectra showed that the absorption peaks of $\mathrm{MO}$ at around $460 \mathrm{~nm}$ dropped obviously within 2 minutes; while the absorbance intensity of the other dyes decreased only slightly. The selective adsorption of MO from the $\mathrm{MO} / \mathrm{MB}$ or the $\mathrm{MO} / \mathrm{RhB}$ mixtures is ascribed to the electrostatic interactions of the anionic MO molecules and the cationic framework of $1 .^{16}$

\section{Adsorption capability of 1 towards $\mathrm{Cr}_{2} \mathrm{O}_{7}{ }^{2-}$}

Hexavalent chromium $\mathrm{Cr}(\mathrm{VI})$, classified as a Group ' $\mathrm{A}$ ' human carcinogen by the U.S. Environment Protection Agency (EPA), has been extensively used in various industries, such as leather tanning, paint making and steel manufacturing. ${ }^{17}$ Inspired by the selective adsorption of anionic methyl orange, the performance of 1 in the removal of $\mathrm{Cr}_{2} \mathrm{O}_{7}{ }^{2-}$ from aqueous solutions was studied. The adsorption experiments were run as follows: $10 \mathrm{mg}$ of 1 was immersed in $15 \mathrm{~mL}$ of $\mathrm{K}_{2} \mathrm{Cr}_{2} \mathrm{O}_{7}$ aqueous solutions $\left(50 \mathrm{mg} \mathrm{L}^{-1}\right)$. The clear solution was measured after centrifuging using UV/vis spectroscopy at $350 \mathrm{~nm}$ to monitor
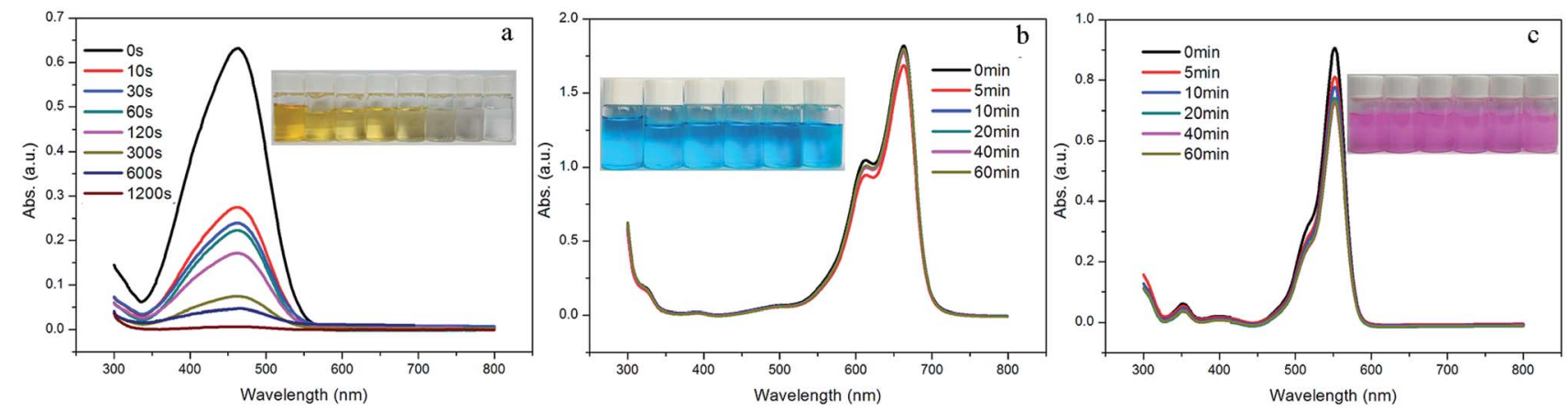

Fig. 2 UV-vis spectra of (a) MO, (b) MB, and (c) RhB with sample 1 at given time intervals. Inset: photographic images of the dye solutions taken at different times. 

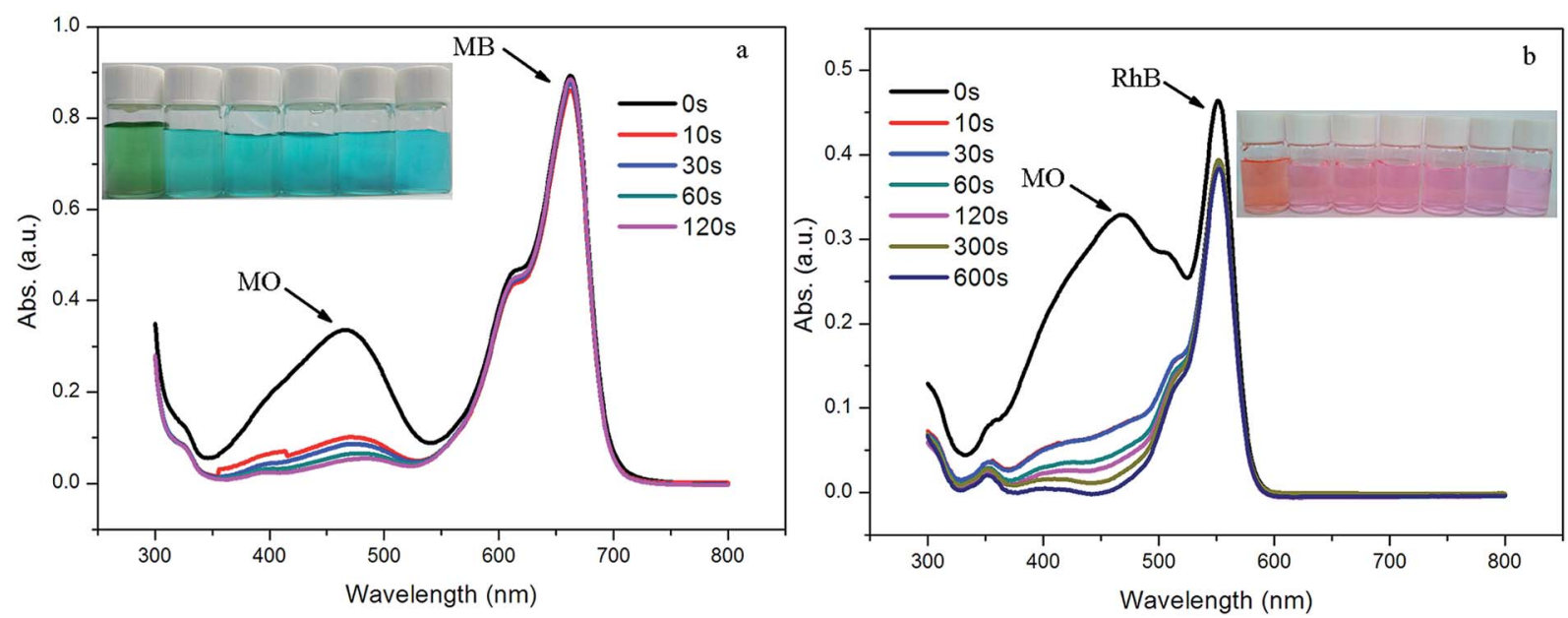

Fig. 3 UV/vis spectra of the dye absorption to evaluate the selective adsorption capability of 1 toward MO from mixed dyes: (a) MO and MB and (b) $\mathrm{MO}$ and RhB. Inset: photographic images of the mixed dye solutions before and after selective adsorption experiments at given time intervals.

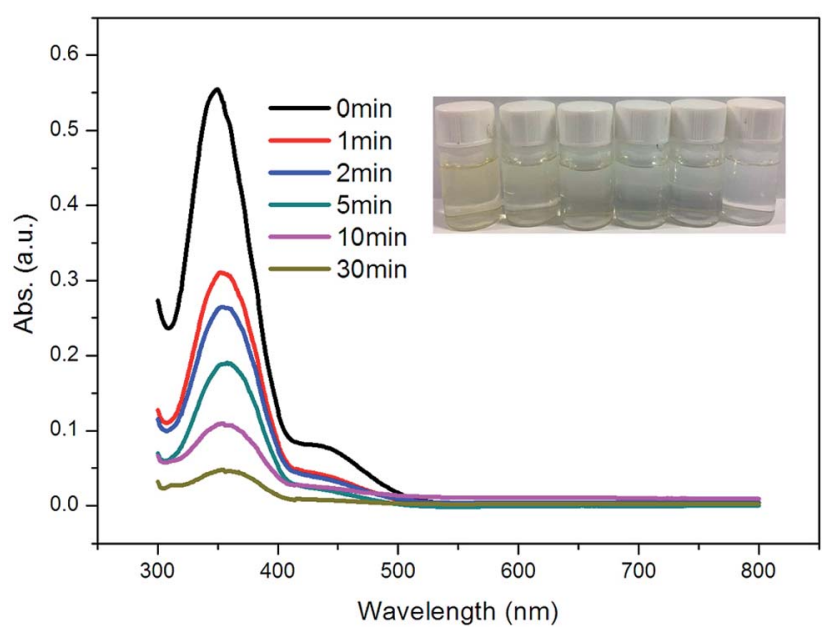

Fig. 4 UV-vis spectra of $\mathrm{Cr}_{2} \mathrm{O}_{7}{ }^{2-}$ with sample 1 at given time intervals. Inset: photographic images of $\mathrm{Cr}_{2} \mathrm{O}_{7}{ }^{2-}$ solutions taken at different times.

the $\mathrm{Cr}_{2} \mathrm{O}_{7}{ }^{2-}$ concentration at different time intervals. As shown in Fig. 4 , the $\mathrm{Cr}_{2} \mathrm{O}_{7}{ }^{2-}$ concentration decreased quickly to $56 \%$ in one minute. At approximately 30 minutes, over $91 \%$ of $\mathrm{Cr}_{2} \mathrm{O}_{7}{ }^{2-}$ can be removed from the aqueous solution. The result indicates that $\mathrm{Cr}_{2} \mathrm{O}_{7}{ }^{2-}$ in the solution promptly entered the channels in $\mathbf{1}$ by exchange with $\mathrm{NO}_{3}{ }^{-}$.

To further evaluate the adsorption capacities of $\mathbf{1}$ toward $\mathrm{Cr}_{2} \mathrm{O}_{7}{ }^{2-}$, the adsorption isotherms were collected accordingly for $\mathbf{1}$ at room temperature (Fig. 5). As the uptake was greatly influenced by the concentration of the $\mathrm{Cr}_{2} \mathrm{O}_{7}{ }^{2-}$ solution, different concentrations of the $\mathrm{Cr}_{2} \mathrm{O}_{7}{ }^{2-}$ solution in the range of 50-600 $\mathrm{mg} \mathrm{L}^{-1}$ were used to determine the uptake. Several batches of sample $\mathbf{1}(10 \mathrm{mg})$ were added to beakers containing the $\mathrm{Cr}_{2} \mathrm{O}_{7}{ }^{2-}$ solution $(15 \mathrm{~mL})$ at different concentrations. The beakers were sealed and then agitated in a magnetic stirrer for 2 hours. Then UV/vis spectra were used to analyse the concentrations of the $\mathrm{Cr}_{2} \mathrm{O}_{7}^{2-}$ solutions until the adsorption process had reached equilibrium. The overall adsorption capacity of 1 for $\mathrm{Cr}_{2} \mathrm{O}_{7}{ }^{2-}$ reaches $228 \mathrm{mg} \mathrm{g}{ }^{-1}$, which is among the highest values for MOF adsorbents used for $\mathrm{Cr}_{2} \mathrm{O}_{7}{ }^{2-}$ removal (Table 1). It should be noted that assuming all nitrates are replaced by $\mathrm{Cr}_{2} \mathrm{O}_{7}{ }^{2-}$, the theoretical maximum adsorption capacity of $\mathrm{Cr}_{2} \mathrm{O}_{7}{ }^{2-}$ is $137.2 \mathrm{mg} \mathrm{g}^{-1}$, far below the experimental value. Therefore, the high space vacuum of the cationic framework (occupied by $\mathrm{NO}_{3}{ }^{-}$and solvent molecules) favors the capture of anionic $\mathrm{Cr}_{2} \mathrm{O}_{7}^{2-}$.

Given the high capacity and fast ion-exchange function of $\mathbf{1}$, selective adsorption tests of $\mathbf{1}$ were carried out by adding a variety of interfering anions including $\mathrm{Cl}^{-}, \mathrm{Br}^{-}, \mathrm{I}^{-}, \mathrm{NO}_{3}{ }^{-}$and $\mathrm{SO}_{4}{ }^{2-}$ to the solution. $10 \mathrm{mg}$ of 1 was immersed in $15 \mathrm{~mL}$ of a solution of $\mathrm{K}_{2} \mathrm{Cr}_{2} \mathrm{O}_{7}\left(50 \mathrm{mg} \mathrm{L}{ }^{-1}\right)$ together with a 5 -fold molar excess of interfering ions and agitated in a magnetic stirrer for 2 hours. The UV/vis spectrum indicates that adding interfering

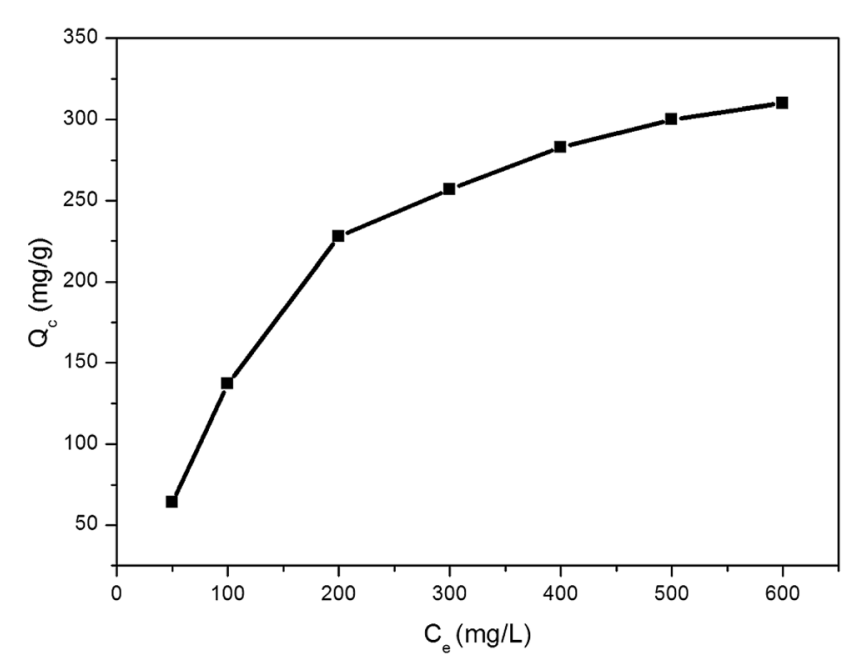

Fig. 5 Adsorption isotherms for the $\mathrm{Cr}_{2} \mathrm{O}_{7}{ }^{2-}$ adsorption over $1, \mathrm{C}_{\mathrm{e}}$ : equilibrium concentration of adsorbate, $Q_{c}$ : amount of $\mathrm{Cr}_{2} \mathrm{O}_{7}{ }^{2-}$ adsorbed. 
Table 1 Comparison of the adsorption capacities for $\mathrm{Cr}_{2} \mathrm{O}_{7}{ }^{2-}$ of MOFbased adsorbents

\begin{tabular}{lll}
\hline MOF-type adsorbents & $\begin{array}{l}\text { Uptake capacity } \\
\left(\mathrm{mg} \mathrm{g}^{-1}\right)\end{array}$ & Ref. \\
\hline SLUG-21 & 60.0 & 18 \\
3D Dy-MOFs & 62.9 & 19 \\
Zn $_{0.5} \mathrm{Co}_{0.5}$-SLUG-35 & 68.5 & 20 \\
FIR-53 & 74.2 & 21 \\
FIR-54 & 103.1 & 21 \\
1 & 228 & This work \\
ZJU-101 & 243 & 22
\end{tabular}

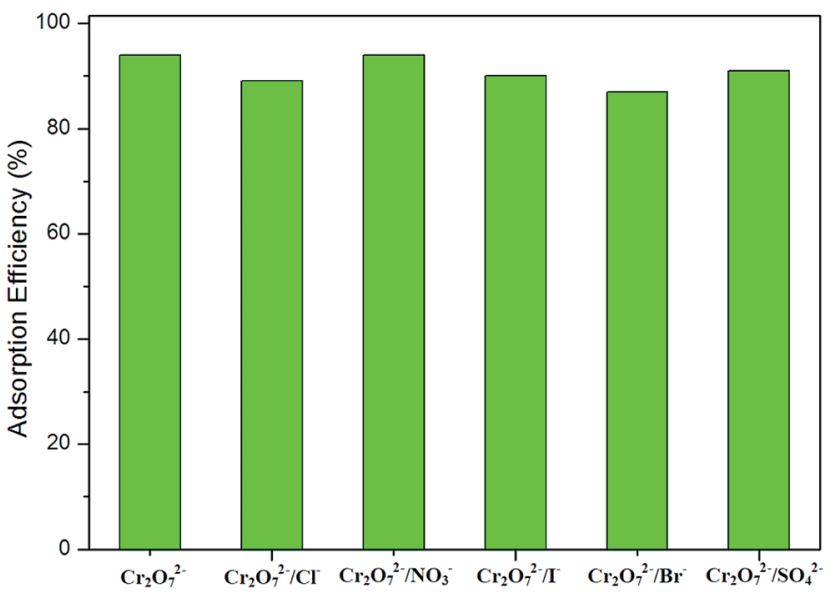

Fig. 6 The adsorption efficiency of 1 towards $\mathrm{Cr}_{2} \mathrm{O}_{7}{ }^{2-}$ in the presence of interfering ions.

ions has little impact on the $\mathrm{Cr}_{2} \mathrm{O}_{7}{ }^{2-}$ adsorption of $\mathbf{1}$ (Fig. 6). In view of the size and charge numbers of the interfering ions, it can be concluded that the highly selective adsorption may be ascribed to the strong coulombic attraction between the framework and $\mathrm{Cr}_{2} \mathrm{O}_{7}{ }^{2-}$ and to the matching of $\mathrm{Cr}_{2} \mathrm{O}_{7}{ }^{2-}$ with the pores.

\section{Conclusions}

In summary, a new MOF has been successfully synthesized by a tripodal neutral ligand. This compound consists of a cationic framework with large-scale channels. Through ion exchange, this compound exhibits rapid and selective separation of methyl orange. Meanwhile, it also shows efficient removal of $\mathrm{Cr}_{2} \mathrm{O}_{7}{ }^{2-}$ from aqueous solutions with a high uptake of up to $228 \mathrm{mg} \mathrm{g}^{-1}$. The results reveal that such cationic framework materials have potential applications in the separation of anionic organic dyes and toxic heavy-metal ions from polluted water.

\section{Conflicts of interest}

There are no conflicts to declare.

\section{Acknowledgements}

The authors gratefully acknowledge the financial support for this work from the National Natural Science Foundation of China (No. 21601019), Jilin Natural Science Foundation of China (No. 20160414031GH) and the Natural Science Foundation of Changchun Normal University (cscxy2017004 and cxcxy2017028).

\section{Notes and references}

1 (a) H. Xue, Q. H. Chen, F. L. Jiang, D. Q. Yuan, G. X. Lv, L. F. Liang, L. Y. Liu and M. C. Hong, Chem. Sci., 2016, 7, 5983; (b) V. Suba and G. Rathika, J. Adv. Phys., 2016, 5, 277; (c) A. V. Desai, B. Manna, A. Karmakar, A. Sahu and S. K. Ghosh, Angew. Chem., Int. Ed., 2016, 55, 7811; (d) S. X. Duan, J. X. Li, X. Liu, Y. N. Wang, S. Y. Zeng, D. D. Shao and T. Hayat, ACS Sustainable Chem. Eng., 2016, 4, 3368.

2 (a) V. K. Gupta and T. A. Saleh, Environ. Sci. Pollut. Res., 2013, 20, 2828; (b) A. Dey, S. K. Konavarapu, H. S. Sasmal and K. Biradha, Cryst. Growth Des., 2016, 16, 5976; (c) R. Bibi, L. F. Wei, Q. H. Shen, W. Tian, O. Oderinde, N. X. Li and J. C. Zhou, J. Chem. Eng. Data, 2017, 62, 1615.

3 F. M. Machado, S. A. Carmalin, E. C. Lima, S. L. P. Dias, L. D. T. Prola, C. Saucier, I. M. Jauris, I. Zanella and S. B. Fagan, J. Phys. Chem. C, 2016, 120, 18296.

4 N. Peng, D. Y. Hu, J. Zeng, Y. Li, L. Liang and C. Y. Chang, ACS Sustainable Chem. Eng., 2016, 4, 7217.

5 V. K. Gupta and A. Nayak, Chem. Eng. J., 2012, 180, 81.

6 C. C. de Escobar, A. Fisch and J. H. Z. dos Santos, Ind. Eng. Chem. Res., 2015, 54, 254.

7 L. C. de Santa Maria, M. R. Aguiar, P. D'Elia, L. O. Ferreira and S. H. Wang, Mater. Lett., 2007, 61, 3395.

8 (a) W. X. Chen, Y. F. Gao, P. Y. Gao, Q. P. Liu and G. L. Zhuang, $R S C A d v$., 2016, 6, 71952; (b) W. X. Chen, L. Tan, Q. P. Liu, G. R. Qiang and G. L. Zhuang, Dalton Trans., 2014, 43, 16515; (c) J. B. Guo, L. H. Chen, D. Li, H. X. Zhao, X. W. Dong, L. S. Long, R. B. Huang and L. S. Zheng, Appl. Phys. Lett., 2017, 110, 192902.

9 (a) N. S. Bobbitt, M. L. Mendonca, A. J. Howarth, T. Islamoglu, J. T. Hupp, O. K. Farha and R. Q. Snurr, Chem. Soc. Rev., 2017, 46, 3357; (b) S. T. Zheng, T. Wu, C. T. Chou, A. Fuhr, P. Y. Feng and X. H. Bu, J. Am. Chem. Soc., 2012, 134, 4517; (c) J. S. Qin, D. Y. Du, M. Li, X. Z. Lian, L. Z. Dong, M. Bosch, Z. M. Su, Q. Zhang, S. L. Li, Y. Q. Lan, S. Yuan and H. C. Zhou, J. Am. Chem. Soc., 2016, 138, 5299; (d) Y. B. He, W. Zhou, G. D. Qian and B. L. Chen, Chem. Soc. Rev., 2014, 43, 5657; (e) M. O'Keeffe and O. M. Yaghi, Chem. Rev., 2014, 114, 1343; (f) X. Chen, B. Q. Zhang, F. Yu, M. Su, W. M. Qin, B. Li, G. L. Zhuang and T. L. Zhang, CrystEngComm, 2016, 18, 6396.

10 (a) M. Kim, J. F. Cahill, H. H. Fei, K. A. Prather and S. M. Cohen, J. Am. Chem. Soc., 2012, 134, 18082; (b) J. Liang, R. P. Chen, X. Y. Wang, T. T. Liu, X. S. Wang, Y. B. Huang and R. Cao, Chem. Sci., 2017, 8, 1570; (c) Y. Lu and B. Yan, J. Mater. Chem. C, 2014, 2, 7411; (d) S. N. Zhao, 
X. Z. Song, M. Zhu, X. Meng, L. L. Wu, J. Feng, S. Y. Song and H. J. Zhang, Chem.-Eur. J., 2015, 21, 9748.

11 (a) X. M. Xian, Y. N. Yan, H. D. Guo, Y. J. Qi and C. M. Liu, CrystEngComm, 2016, 18, 2546; (b) H. D. Guo, X. M. Guo, H. Y. Zou, Y. J. Qi and R. Z. Chen, CrystEngComm, 2014, 16, 2176.

12 G. M. Sheldrick, SHELXS-97, Programs for X-ray Crystal Structure Solution, University of Göttingen, Göttingen, Germany, 1997.

13 G. M. Sheldrick, SHELXL-97, Programs for X-ray Crystal Structure Refinement, University of Göttingen, Göttingen, Germany, 1997.

14 A. Spek, Acta Crystallogr., Sect. D: Biol. Crystallogr., 2009, 65, 148.

15 (a) Y. Y. Jia, G. J. Ren, A. L. Li, L. Z. Zhang, R. Feng, Y. H. Zhang and X. H. Bu, Cryst. Growth Des., 2016, 16, 5593; (b) Y. L. Li, Y. Zhao, P. Wang, Y. S. Kang, Q. Liu, X. D. Zhang and W. Y. Sun, Inorg. Chem., 2016, 55, 11821; (c) N. C. Burtch, H. Jasuja and K. S. Walton, Chem. Rev., 2014, 114, 10575.

16 (a) W. W. He, S. L. Li, K. Z. Shao, Z. M. Su and Y. Q. Lan, Chem.-Eur. J., 2016, 22, 17298; (b) Y. Q. Lan, H. L. Jiang, S. L. Li and Q. Xu, Adv. Mater., 2011, 23, 5015.

17 J. J. Testa, M. A. Grela and M. I. Litter, Environ. Sci. Technol., 2004, 38, 1589.

18 H. H. Fei, M. R. Bresler and S. R. J. Oliver, J. Am. Chem. Soc., 2011, 133, 11110.

19 P. F. Shi, B. Zhao, G. Xiong, Y. L. Hou and P. Cheng, Chem. Commun., 2012, 48, 8231.

20 H. H. Fei, C. S. Han, J. C. Robins and S. R. J. Oliver, Chem. Mater., 2013, 25, 647.

21 H. R. Fu, Z. X. Xu and J. Zhang, Chem. Mater., 2015, 27, 205.

22 Q. Zhang, J. C. Yu, J. F. Cai, L. Zhang, Y. J. Cui, Y. Yang, B. L. Chen and G. D. Qian, Chem. Commun., 2015, 51, 14732 . 